\title{
Using digital platforms to promote a service-oriented logic in public sector organizations: A case study
}

\author{
Kathrine Vestues \\ Norwegian University of Science \\ and Technology (NTNU) \\ kathrine.vestues@ntnu.no
}

\author{
Marius Mikalsen \\ SINTEF, Trondheim, Norway. \\ Norwegian University of Science \\ and Technology (NTNU) \\ marius.mikalsen@sintef.no
}

\author{
Eric Monteiro \\ Norwegian University of Science \\ and Technology (NTNU) \\ eric.monteiro@ntnu.no
}

\begin{abstract}
A growing number of scholars and practitioners have recognized that value is defined and cocreated by citizens and that citizens must be involved in the service delivery process to improve the quality and efficacy of public services. Central to this servicedominant logic is that public sector organizations cannot manufacture value for citizens; they can only make a value proposition that the citizen might choose to use. Hence, value must be cocreated. However, this cocreation entails accommodating cocreation practices with millions of users. Currently, cocreation is often limited to involving a carefully selected set of users in crafting requirements early and/or measuring user satisfaction upon service launch. There is an empirical blindspot in the current literature in terms of how to shape service delivery in a way that is capable of effectively capturing emergent and process-oriented value cocreation across large user groups. Through a longitudinal case study of the IT department at the Norwegian Labour and Welfare Administration (NAV), which provides services to millions of users, this paper explores how digital platforms are used to transform value cocreation into a process of continuous improvement. We find that adopting a process-oriented approach for cocreation within public sector organizations requires structural changes, including sourcing strategy and governance structure. We also show the importance of digital platforms in increasing the efficiency of cocreation. We discuss how these structural changes were made and the role played by digital platforms in achieving these changes.
\end{abstract}

\section{Introduction}

Public sector organizations are under strong and increasing pressure to improve their service delivery. In particular, issues have been raised about inadequate response to emergent demands [1, 2] and lack of citizen involvement [3].

This calls for a transformation of public sector organizations where they become more attuned to citizens' demand for emergent service delivery, with a focus on value creation as a process where value is cocreated and negotiated through the ongoing collaboration between public sector organizations and citizens. Crucially, this underscores the importance of recognizing the context-dependent and emergent nature of value, where the perceived value of a service will change in line with changing user expectations and knowledge. Successful service delivery therefore requires a longer-term, process-oriented approach where public sector organizations continuously seek knowledge, feedback and information from citizens, which in turn are used to continuously improve service delivery.

In practice, adopting a process-oriented approach has proven difficult. Citizen input and feedback are generally used to cocreate requirements at the beginning of a project or measure user satisfaction after services are launched [4]. This signifies the remains of a manufacturing-oriented logic that effectively obstructs public sector organizations' capability to respond to emergent citizen needs [3].

The existing literature predominantly focuses on cocreation during early design and specification phases, where user feedback is directly transmitted from citizens to service providers [5-8]. However, to achieve the promises of a service dominant logic $[3$, 9], there is a need to address cocreation as an ongoing process, where cocreation is mediated throughout the entire service delivery cycle. Public administrators are therefore exploring novel means to achieve more agile and continuous value cocreation [10]. In this regard, digital platforms have significant potential to realize a more process-oriented approach. This is due to the digital platform's ability to mediate between service 
providers and users and scale up user engagement through mediated forms of cocreation $[11,12]$.

Recently, calls have been made for improved insight into the ways in which feedback from users is captured and reintegrated at a service level and the role of technology in such forms of value cocreation [5, 13]. Answering to these calls, this paper examines the following research question: How do digital platforms promote process-oriented, mediated value cocreation in public sector organizations?

To answer this question, we draw on insights from a longitudinal case study of the IT department in the Norwegian Labour and Welfare Administration (NAV). NAV serves millions of users, has almost 19 000 employees and is responsible for redistributing one third of the national budget through schemes such as age pension, sick-benefit, and disability benefit. In 2017, NAV made radical changes to its service delivery model, moving from a manufacturingoriented approach towards more process-oriented service delivery. We aim to contribute by explaining how adopting a process-oriented approach for value cocreation in NAV required structural changes, including sourcing strategy and governance structure. We also show the key role of digital platforms in capturing and reintegrating feedback into subsequent service delivery cycles.

The rest of the paper is organized as follows: In section 2, we present an overview of the literature on value cocreation, followed by a review of the literature on digital platforms within the public sector, before we present the theoretical framework that was used to analyze our data. In section 3, we describe the research setting and methods, while section 4 presents our findings. Finally, in section 5, we discuss how these structural changes were possible and the role of digital platforms in achieving these changes before making concluding remarks.

\section{Theoretical background}

Value cocreation denotes a logic of value creation where value is seen as created in the interaction between provider and users [9, 14]. In the following sections, we begin by discussing value cocreation in the public administration literature before exploring the way in which digital platforms might affect value cocreation. Finally, we present our theoretical framework.

\subsection{Cocreating public services}

Public sector organizations have traditionally been dominated by a manufacturing logic, where value is seen as created by a service organization and delivered to citizens who take the role of passive consumers. This logic has, however, come under increasing criticism for failing to address the complex, fragmented, and emergent needs of citizens [3, 13, 15]

As a consequence, researchers have identified an alternative logic, where value is seen as cocreated in the interaction between public sector organizations and citizens $[9,15]$. Central to this service-dominant logic is that public sector organizations cannot create value for citizens - they can only make a "value proposition" that the citizen might choose to use $[3,9]$. Hence, value is created in use ("value-in-use") [3].

Furthermore, service-dominant logic emphasizes that value propositions and their potential to create value for citizens depend on the social context in which the service is offered [16]. As the context changes, for instance, as citizens acquire new knowledge or appropriate new technology, preferences and needs will change. If services are to be perceived as valuable over time, public sector organizations must therefore continuously seek feedback from citizens and improve value propositions accordingly. The ability to sense and respond to evolving needs requires agility and responsiveness on the part of public sector organizations, often contradicting established structures that favor internal efficiency over external efficacy [13].

A founding idea in service-dominant logic is that value is cocreated through the interaction between suppliers and users. It pinpoints the challenge of shifting from a supply-side focus in the delivery of public services to a demand-side focus. There are, however, three shortcomings in the manner in which value cocreation has been employed in the context of public sector services. First, the cocreation between citizens and the supply side is assumed to take the form of direct engagement and interaction. For all its merit, direct involvement of citizens is only feasible for small populations; the scaling of participatory methods of technology development by necessity needs to find indirect, mediated forms of representing citizens' voices [17, 18]. Second, common for much of this research is an emphasis on "the involvement of citizens in the initiation and/or design of public services" [8], most often neglecting cocreation in later stages of service delivery [13]. Third, the extant literature pays little attention to the role of communication technology in promoting value cocreation in public sector organizations $[5,13]$.

Recently, digital platforms have emerged as a promising approach to transforming public sector organizations and increasing the capacity for cocreation. In the following section, we give a short overview of the way digital platforms have been 
addressed in the public administration literature and discuss the way in which platforms might enable increased value cocreation.

\subsection{Digital platforms in the public sector}

Digital platforms enable innovation [12], value cocreation [19], and user involvement [11] and have been studied as a means for increasing public and private value creation [20]. From an economic perspective, platforms create value by acting as mediators between two or more categories of users who would otherwise not connect [21, 22], while they, from an engineering perspective, are seen as technology foundations that enhance generativity and innovation through their layered modular structure $[12,23]$.

The advent of platform ecosystems is radically transforming the way private and public sector organizations interact with their users. Digital platforms let governments tap into existing communication channels [24, 25], thereby engaging citizens in the arenas they know. For instance, Hand and Ching [26] examine how social media platforms such as Facebook and Twitter let citizens engage with police agencies, while Nam [27] explores the way in which digital platforms enable discussions about rule making between citizens and other stakeholders. Similarly, many studies explore the challenges and opportunities relating to open government data, focusing on issues such as innovation [28], civic engagement [29], and the design of open data platforms [30]. Public sector platforms can potentially increase both transparency and efficiency by exposing public sector data and engaging citizens in cocreation [31].

While the debate on digital platforms has proven useful, much of the existing literature has focused on digital platforms as a means for communication between public sector organizations and citizens. As an exception to this trend, Dunleavy et al. [32] argue that we have entered an era of digital governance, where public sector developments revolve around changes in digital technologies and alterations in information systems. By reintegrating public service, digital technologies are enabling a "needs-based holism" where end-to-end processes and agile practices are increasing public sector organizations' ability to respond to emerging citizen needs [32]. Similarly, Fishenden and Thompson [33] propose that digital platforms and open architectures enable a reaggregation of digital services, promoting a servicedominant approach where citizens become an integral part of the value creation process. Central to this transformative potential is the platform's ability to mediate between different user groups and offer resources that can be recombined into new and improved services. Hence, the platform becomes a venue where citizens and public sector organizations can interact and exchange services and information. Digital platforms are thus important in public sector service delivery for at least two reasons. First, digital platforms facilitate the exchange of services and information between citizens and public sector organizations. Second, platforms enable a rapid and ongoing reintegration of this information into new and improved value offerings [14].

\subsection{Processual perspective on value cocreation}

Digitally enabled participation and production of services is changing citizens' expectations about public sector services [34]. To ensure continued trust in governments, public sector organizations need to move from anticipating citizens' needs (manufacturing-oriented approaches) to approaches where services are developed in response to the actual needs of citizens. Although prior literature on value cocreation has recognized the need for an alternative logic in public sector organizations, it provides little insight into how such value cocreation can be achieved in practice $[3,13]$. We argue that traditional forms of cocreation are poorly suited for the large-scale and dynamic context of public sector organizations.

To close this gap, there are several assumptions worth making. First, direct involvement as the sole means for capturing citizen feedback is insufficient for collecting the needs of large and heterogeneous user groups. Instead, organizations need to adopt practices that enable indirect and mediated forms of interaction where feedback can be gathered from large user groups. Second, feedback must be collected and reintegrated throughout the service delivery cycle, not only during initiation and design. Third, to adopt cocreation across organizations, traditional structures of centralization and control must be replaced by more flexible technical and organizational structures that enable agility and innovation.

To further our understanding of how public sector organizations can achieve ongoing value cocreation, we have conducted a case study of NAV. During the past few years, NAV has undergone radical changes to the way it develops and delivers public services, moving from a manufacturing-oriented approach towards a more service-dominant logic. In the following sections, we describe the methods used to investigate the transformation and the results we obtained. 


\section{Research setting and methods}

Fieldwork was conducted within the IT department at the Norwegian Labour and Welfare Administration (NAV). The IT department consists of approximately 700 employees, 400 consultants, and operates and maintains close to 300 applications.

NAV was established in 2006, following the merger of the Employment Agency, the National Insurance Agency, and Social Services. NAV is responsible for increasing the population's work ability, as well as supporting citizens economically during periods when they are unable to support themselves. Among the services they provide are age pensions, unemployment benefits, sick benefits, and disability benefits. Most Norwegian citizens will at some point come in contact with NAV. The organization has almost 2.8 million active users at any given time.

In 2015, an expert committee criticized NAV for failing to improve digital services in response to emergent needs and for paying too little attention to user experiences [35]. As a response to this criticism, NAV made radical changes to its sourcing strategy, technical infrastructure, and governance model.

To examine these changes, we performed an interpretive longitudinal case study. Data were collected over a two-year period from January 2017 to May 2019 and consisted of document analysis, participant observation, and semi structured interviews. The study of the ongoing change process was complemented by a historical reconstruction based on archived documents and informants' recollection of the past.

First, we conducted a total of 38 interviews. We chose informants using a snowballing strategy, where one informant suggested the next. In this way, we gradually traversed the IT department, including informants from all levels of the organization. Among informants were the former and present CTO (2), program and department managers (4), project managers (4), team leads (6), IT architects (8), software developers (12), and case workers (2). These differing perspectives were important to capture both the strategic motivations behind the change and its practical implications. For instance, CTOs, senior executives, and managers were able to shed light on the motivations and larger context, whereas IT architects, team leads, and developers provided insight into the technical implementation and their consequences.

Of the 38 interviews, 23 were recorded and transcribed. Because of their sensitive nature, not all interviews could be recorded. In these cases, we took notes during interviews and added more extensive remarks after the interviews ended. Interviews lasted between 45 and 60 minutes.

Second, participant observation was another important source of information. The first author was able to move freely within the IT department and could also attend most meetings and social gatherings. She has a background as a software developer and IT consultant and could easily blend into the environment. Considerable insight was gained through informal conversations by the coffee machine and encounters in the hallway. Many of the informants were recruited through this informal relation building. Observations and conversations were extensively documented in a field diary.

Third, our study included numerous documents collected from internal and external web sites and archiving systems. Among these were governmental white papers, procurement documents, design specifications, project reports, and websites. The first author was given an internal account and could access most internal documents, including calendars, project wikis, and issue tracking systems. In addition, online conference presentations held by NAV employees were transcribed and analyzed. Since the digital platform used to facilitate the shift was exposed as open-source code on GitHub, we were able to examine its functionality in great detail (www.nais.io), including features relating to monitoring and feedback.

Data collection and data analysis were performed in tandem to benefit from the understanding emerging from recursively iterating between theoretical conceptions and the empirical material [36]. Specifically, our data analysis can be described as an iterative three-step process. First, interviews were transcribed and coded. We used descriptive codes, capturing the informant's views and reflections on the transformation. For instance, the code "The platform is used to change the organizational culture" captures the interaction between technology and organization, where the introduction of the platform was seen to enable social change. Codes were later merged into 3 themes that captured relevant aspects of the transformation of NAV. The themes are listed in Tables 1 and 2 .

Second, we used visual mapping to display the progression of events between 2012 and 2019. By using a method of temporal bracketing [37], we identified two periods in which service delivery was approached in distinctly different ways: The first period $(2012-2016)$ was dominated by large projects with staged development and limited user input, whereas the second period $(2017$ - 2019) was characterized by incremental approaches where user 
feedback was continuously monitored and reintegrated into subsequent service delivery.

Third, we iterated between theoretical abstractions relating to service-dominant logic and themes uncovered in the previous phase of analysis. Elements of manufacturing logic mapped accurately to the first period, whereas the last period was characterized by service-dominant logic. Based on the analysis, we inferred that NAV had transitioned from a manufacturing logic to a service-dominant logic and that the change was captured by elements relating to 1) sourcing strategy, 2) technical platform, and 3) governance model.

\section{Results}

In the following, we present the two time periods uncovered in our analysis and describe the alternative ways in which the sourcing strategy, technical platform, and governance model were addressed in each of the two periods.

\subsection{Manufacturing logic (2012 - 2016)}

From 2012 to 2016, software development in NAV was organized as large projects where development and maintenance were outsourced to consultant companies. Information systems were large and interconnected, and projects followed a staged delivery model where requirements elicitation and user involvement were isolated to early stages of the development process. Dependencies were managed through centralized control and coordinated releases. The elements are summarized in Table 1 and elaborated on in three subsections.

Table 1. Elements of manufacturing logic

\begin{tabular}{|l|l|}
\hline Element & Contents \\
\hline $\begin{array}{l}\text { Sourcing } \\
\text { strategy }\end{array}$ & $\begin{array}{l}\text { Service development was organized } \\
\text { as large projects where the software } \\
\text { development was outsourced to } \\
\text { consultant companies }\end{array}$ \\
\hline $\begin{array}{l}\text { Technical } \\
\text { platform }\end{array}$ & $\begin{array}{l}\text { Large and interdependent IT } \\
\text { systems required coordination and } \\
\text { control }\end{array}$ \\
\hline $\begin{array}{l}\text { Governance } \\
\text { strategy }\end{array}$ & $\begin{array}{l}\text { Staged development methods and } \\
\text { centralized control restricted user } \\
\text { involvement to early stages }\end{array}$ \\
\hline
\end{tabular}

4.1.1. Sourcing strategy. In the period from 2012 to 2016, IT development was organized as large projects where the development and maintenance of information systems were outsourced to consultant companies. To ensure predictability and control, NAV introduced a clear separation between customers and suppliers, where requirements elicitation and user involvement were isolated to early stages of the development process. Changes to the agreed-upon requirements often required formal approval and additional funding, limiting the organization's ability to respond to emergent needs.

In line with public sector procurement regulations, maintenance contracts were put out to tender every $4-8$ years. In this way, suppliers were replaced at regular intervals, causing discontinuity and loss of key competence. "At any given time, NAV would have 15-20 distinct suppliers developing and maintaining its core systems. These suppliers had to be coordinated and controlled" (CTO).

A significant part of IT modernization in NAV was funded over the national budget. To minimize the administrative overhead associated with such funding, project proposals would contain a large and dispersed collection of prospective needs, increasing both complexity and risk.

A prominent example of this funding model was a large modernization program that was initiated in 2012. The main purpose of the program was to renew NAV's IT portfolio and increase efficiency through automation and self-service solutions. The program had an estimated cost of 3.3 billion Norwegian Kroner (approx. 349 million U.S. dollars) and would be performed through three consecutive projects-lasting from 2012 until 2018.

4.1.2. Technical platform. After NAV was established in 2006, the system portfolio consisted of large and heterogeneous systems. To reduce technical heterogeneity and simplify operations and management, NAV began to standardize on a single application platform. By 2016, most systems were running on a single application platform. The platform was based on JBoss application servers running on a Red Hat Linux operating system and virtual servers. The goal was to eventually run all applications on the same platform. However, two of the core systems were too large and too tightly connected to the underlying hardware for migration to occur. Thus, by the end of 2016, NAV had three technical platforms: 1) Infotrygd - an IBM mainframe from 1978, 2) Arena - an Oracle forms-based system introduced in 2001, and 3) a JBoss application server running on a Red Hat Linux operating system.

Although technical heterogeneity was reduced, systems were still large and interdependent. To manage these dependencies and ensure stable 
operations, release management was centralized and coordinated across projects. All software releases had to be tested and approved by the operations department. For maximum resource utilization, deployments were bundled into four yearly releases. Although the strategy provided predictability and internal efficiency, it reduced the flexibility and responsiveness of development teams: It could take months from when a feature was developed until it became available to end-users, and teams tried to predict future needs as a means for reducing response times.

4.1.3. Governance strategy. Software development was organized as distinct and nonoverlapping stages, where different departments were responsible for different stages of the development process. For instance, design and specification had to be completed before the project could begin to develop the system, and development had to be finalized and approved before the application could be released into production.

The development strategy reduced the responsiveness of development teams in several ways. First, user input was isolated to early stages of the development process. Second, changes to initial specifications required formal approval and possibly additional funding. Third, it could take years from project initiation until the system was completed and available. During this time, the needs and expectations of users would evolve, and the completed system could become obsolete.

To ensure consistency across suppliers and projects, NAV introduced a centralized governance model and a technology "catalog" listing approved technologies. Any decision to appropriate new technologies or use old technologies in new ways had to be approved by an IT architecture decision board. The strategy increased predictability but effectively reduced local initiatives and innovation.

\subsection{Service-dominant logic}

Following the criticism of the expert committee in 2015 [35], NAV made several changes to its digital service strategy. First, the outsourcing strategy was replaced by an insourcing strategy. Second, monolithic systems were gradually dismantled into more loosely coupled applications. Third, the staged software development method was developed by an iterative approach where development teams were developed and maintained by independent teams responsible for the entire service delivery cycle. Table 2 summarizes these changes.
Table 2. Elements of a service-dominant logic

\begin{tabular}{|l|l|}
\hline Element & Contents \\
\hline $\begin{array}{l}\text { Sourcing } \\
\text { strategy }\end{array}$ & $\begin{array}{l}\text { Insourcing of software } \\
\text { development where software } \\
\text { development activities are funded } \\
\text { over the operating budget }\end{array}$ \\
\hline $\begin{array}{l}\text { Technical } \\
\text { platform }\end{array}$ & $\begin{array}{l}\text { Monolithic and interdependent } \\
\text { applications are dismantled into } \\
\text { more loosely coupled applications }\end{array}$ \\
\hline $\begin{array}{l}\text { Governance } \\
\text { strategy }\end{array}$ & $\begin{array}{l}\text { Independent teams assume } \\
\text { responsibility for the entire } \\
\text { software development cycle }\end{array}$ \\
\hline
\end{tabular}

4.2.1. Sourcing strategy. NAV changed its sourcing strategy in 2017. The outsourcing of software development was replaced by an insourcing strategy where NAV would assume responsibility for developing and maintaining core systems. As the old contracts expired, responsibility contracts were replaced by capacity contracts where consultants were hired per hour. The long-term objective was that consultants would only be used during peak periods and to provide specialized competence.

To accommodate the new sourcing strategy, NAV began an aggressive recruitment campaign, aiming to employ hundreds of software developers within a few years. During the two years the study lasted, NAV recruited close to 200 developers. Competitive salaries and promises of modern technologies made NAV an attractive employer. A key objective behind the insourcing strategy was to strengthen internal competence and provide continuity and learning.

The altered strategy also affected the funding model: Although service development still required external funding, the funding was used to finance existing teams. By maintaining stable teams with stable responsibilities, continuity and predictability were increased. This stood in stark contrast to the manufacturing-oriented approach, where periods of intense activity were followed by periods of relative calm. The long-term goal was for the organization to become less dependent on external funding and that most development activities be financed over the operating budget.

4.2.2. Technical platform. To increase the flexibility and maintainability, NAV began to dismantle legacy systems into more loosely coupled applications. To facilitate the dismantling of legacy systems, NAV introduced a second-generation application platform in 2017. The application platform was called "NAIS", 
short for NAV's Application Infrastructure Service and was based on Kubernetes. Kubernetes is an opensource framework developed by Google. The platform offers fully automated services for tasks such as provisioning and deployment. As expressed by a member of the platform development team, "Kubernetes is the open source framework that comes from Google. It is all of Google's experience over the last 15 years with how to manage infrastructure rewritten by the same people. It is such as taking the world's best operations person and fully automating him. That is what Kubernetes is. It provides many tools for running in production, which makes it more robust and more scalable and everything".

The NAIS platform also simplified the monitoring of application performance and use. These metrics were displayed on a large screen in the team area, providing development teams with immediate and continuous feedback from systems and users. Through this mediated interaction with citizens, development teams were able to continuously improve services in response to actual use. Mediated feedback from monitoring mechanisms was complemented with traditional forms of direct user input, such as "guerrilla" interviews, surveys, design workshops, and prototyping. Together, these strategies provided the team with rich insight into the application of strong points and shortcomings. The loosely coupled architecture of the platform, combined with functionality for automated provisioning and deployment, enabled development teams to rapidly reintegrate feedback from citizens could into new and improved services.

4.2.3. Governance strategy. The dismantling of legacy systems into a more modular structure enabled a restructuring of the IT department: The staged development model was replaced by an iterative approach where independent teams were responsible for the entire software development cycle. To effectuate this shift, the IT department was reorganized in 2017. The "plan-build-run" hierarchy was replaced by a decentralized control structure where employees were assigned to multidisciplinary service development teams. Team members had various backgrounds, including software developers, interface designers, IT architects, and domain experts.

A leading principle behind the reorganization was that development teams would have the competence and authority to develop services independently of other teams and that they would be responsible for the entire service delivery cycle-from the inception of an idea until the service was eventually turned off.

By duplicating competence across teams and introducing a distributed decision model, development teams could work independently, and release applications as needed. Centralized control and coordinated releases were replaced by decentralized decisions and continuous releases. For many teams, deployment rates increased from once every three months to several times a day. In this way, user feedback was rapidly and continuously reintegrated into service releases.

\section{Discussion}

The purpose of this study was to investigate how digital platforms promote process-oriented, emergent value cocreation in government organizations. Through the research question - how do digital platforms promote process-oriented, emergent value cocreation in government organizations - we have reported findings from an explorative case study of a large public IT department. The study aims to contribute in two important ways. First, we examine the organizational and strategic changes necessary to enable continuous and ongoing value cocreation across large and heterogeneous user groups. Second, we emphasize the role of digital platforms in scaling value cocreation in time and space. Each of these contributions is discussed in further detail below.

\subsection{Process perspective on service delivery}

Extant research discusses the benefits, drivers, and barriers of cocreation in the public sector $[5,7]$ with an emphasis on cocreation as part of the initiation or early design [8]. We complement these studies by exploring the structural changes undertaken by NAV to achieve value cocreation across large and heterogeneous user groups throughout the service delivery cycle.

First, NAV changed the sourcing strategy transitioning from an outsourcing strategy to an insourcing strategy. By employing software developers and gradually replacing consultants with internal employees, NAV ensured continuity and predictability, both in terms of financing and competence. While software development had previously been financed through large-scale projects, software would now become a continuous activity performed by internal employees, financed over the operating budget. This provided predictability and continuity, allowing the organization to build the knowledge and skills required to continuously improve services.

Second, they changed the governance strategy replacing top-down control and handovers between departments with a bottom-up approach, where independent, self-organizing teams were responsible 
for the entire service development cycle [38]. By establishing multidisciplinary teams with the skills, knowledge, and authority to solve problems independently, NAV was able to continuously sense and react to the emergent needs of citizens.

Our findings correspond with insights from service-dominant logic, which suggests that organizations must engage in continuous and ongoing improvements to ensure value cocreation throughout the development cycle [9, 13]. However, our study addresses a blind spot in the current literature by questioning the applicability of direct user interaction as a means for achieving continuous and ongoing value cocreation across large and heterogeneous user groups $[17,18]$. In this way, we complement existing studies by emphasizing the context-dependent and emergent nature of value cocreation, arguing that public sector organizations need to radically restructure their service delivery models and employ mediated forms of feedback and learning.

Although other studies have addressed the need for more responsive service delivery methods in public sector organizations $[1,2,39]$, these studies either do not address the structural changes needed to adopt such approaches [2, 39] or they view agility and responsiveness as "add-ons" that apply in selected cases [1]. In contrast, our study sees value cocreation as a set of processes and activities that are applied across departments and organizations, radically changing the way public sector organizations organize and deliver service.

\subsection{Platforms as enablers}

Our findings suggest that digital platforms play a pivotal role in enabling efficient value cocreation within public sector organizations. At NAV, the container-based application platform enabled cocreation in three important ways. First, the modular structure of the platform enabled the formation of independent development teams that could work in relative isolation. As long as application interfaces remained intact, development teams could experiment and innovate inside the boundaries of their applications [40].

Second, the platform provided indirect and mediated feedback from citizens. By monitoring application use and performance, development teams were able to continuously capture the reactions of citizens. Third, the platform simplified provisioning and deployment, thereby enabling continuous and ongoing reintegration of feedback into subsequent service deliveries. These insights comply with insights from service-dominant logic, which suggest that digital platforms increase both the efficiency and effectiveness of resource exchange [14].

Based on our findings, we further suggest that by enabling mediated feedback and rapid reintegration into subsequent service delivery, platforms have the potential to scale cocreation in both time and space. While other studies explore the ways in which digital platforms enable improved communication between citizens and governments within existing structures $[26,41]$, we thereby take a step further and examine the ways in which platforms might enable the formation of radically new structures and improved forms of service delivery.

Further, we address the relation between the structure of the digital infrastructure and the organization's ability to develop and deliver services, suggesting that the transformation of public sector organizations preconditions a transformation of the digital infrastructure: Only by increasing the flexibility of the infrastructure are organizations able to scale value cocreation across the organization, incorporating feedback from large and heterogeneous user groups over prolonged periods of time.

The focus of our study has been the broad strategic and technical changes needed to move public sector organizations towards more service-dominant logic. To pursue this goal, we have adopted a supplyside focus in the exploration of organizational and technological changes. We have largely ignoring the perceptions of citizens in our exploration of the ongoing transformation. The rationale behind this decision is two-fold: First, capturing both the supply side and demand side in a complex case such as NAV was not possible within the constraints of our research projects. Second, many of NAV's services are part of a larger value chain, including a wide array of public and private actors outside NAV. It will therefore take time before the effects of the ongoing transformation propagate out to citizens. We therefore hold the exploration of citizens' opinions and experiences as an opportunity for future research.

In addition, further research is needed to uncover the long-term effects of such transformations. NAV underwent significant changes during the course of our fieldwork, but considerable work remains.

Further, our research lacks details of the specific monitoring and feedback mechanisms used in the delivery process. Exploring the different forms of mediated feedback and the way in which they evolve over time presents another opportunity for future research.

Finally, our findings are limited to one specific case and context. Exploring the applicability of similar approaches in other public sector contexts thus presents another opportunity for future research. 


\section{Conclusion}

In this paper, we have approached value cocreation as a process of ongoing improvement, where public sector organizations must implement the means to apply feedback and learning throughout the entire service development cycle. We have described how digital platforms promote such service-dominant logic by mediating interaction with citizens and facilitating the reintegration of feedback into subsequent service delivery. We found that adopting a process-oriented approach for value cocreation within public sector organizations requires structural changes, including sourcing strategy, governance structure, and more flexible digital infrastructure.

\section{Acknowledgments}

We would like to thank NAV for granting us access to the sites and all informants for taking the time to talk to us. We would also like to thank Torgeir Dingsøyr for providing valuable comments during the writing of the paper. This work was supported by the project Agile 2.0 supported by the Research Council of Norway through grant 236759 and by the companies DNV GL, Equinor, Kantega, Kongsberg Defense \& Aerospace, Sopra Steria and Sticos.

\section{References}

[1] I. Mergel, N. Edelmann, and N. Haug, "Defining digital transformation: Results from expert interviews," Government Information Quarterly, vol. 36, no. 4, pp. 101385, 2019.

[2] I. Mergel, "Agile innovation management in government: A research agenda," Government Information Quarterly, vol. 33, no. 3, pp. 516523, 2016.

[3] S. P. Osborne, "From public service-dominant logic to public service logic: are public service organizations capable of co-production and value co-creation?," Taylor \& Francis, 2018.

[4] OECD, Digital Government Review of Norway Boosting the digital transformation of the public sector, OECD, OECD Publishing, Paris, 2017.

[5] N. Baptista, H. Alves, and N. Matos, "Public Sector Organizations and Cocreation With Citizens: A Literature Review on Benefits, Drivers, and Barriers," Journal of Nonprofit \& Public Sector Marketing, pp. 1-25, 2019.

[6] J. Trischler, S. J. Pervan, S. J. Kelly, and D. R. Scott, "The value of codesign: The effect of customer involvement in service design teams,"
Journal of Service Research, vol. 21, no. 1, pp. 75-100, 2018.

[7] W. H. Voorberg, V. J. Bekkers, and L. G. Tummers, "A systematic review of co-creation and co-production: Embarking on the social innovation journey," Public Management Review, vol. 17, no. 9, pp. 1333-1357, 2015.

[8] W. Voorberg, V. Bekkers, S. Flemig, K. Timeus, P. Tonurist, and L. Tummers, "Does co-creation impact public service delivery? The importance of state and governance traditions," Public Money \& Management, vol. 37, no. 5, pp. 365-372, 2017.

[9] S. L. Vargo, and R. F. Lusch, "Evolving to a new dominant logic for marketing," Journal of marketing, vol. 68, no. 1, pp. 1-17, 2004.

[10]I. Mergel, S. Ganapati, and A. B. Whitford, "Agile: A New Way of Governing," Public Administration Review, 2020.

[11]B. Eaton, S. Elaluf-Calderwood, C. Sorensen, and Y. Yoo, "Distributed tuning of boundary resources: the case of Apple's iOS service system," MIS Quarterly: Management Information Systems, vol. 39, no. 1, pp. 217-243, 2015.

[12]Y. Yoo, O. Henfridsson, and K. Lyytinen, "Research commentary-the new organizing logic of digital innovation: an agenda for information systems research," Information systems research, vol. 21 , no. 4, pp. 724-735, 2010.

[13]S. P. Osborne, Z. Radnor, and K. Strokosch, "Coproduction and the co-creation of value in public services: a suitable case for treatment?," Public Management Review, vol. 18, no. 5, pp. 639-653, 2016.

[14]R. F. Lusch, and S. Nambisan, "Service innovation: A service-dominant logic perspective," MIS quarterly, vol. 39, no. 1, 2015.

[15]S. P. Osborne, Z. Radnor, and G. Nasi, "A new theory for public service management? Toward a (public) service-dominant approach," The American Review of Public Administration, vol. 43, no. 2, pp. 135-158, 2013.

[16]R. F. Lusch, S. L. Vargo, and M. Tanniru, "Service, value networks and learning," Journal of the academy of marketing science, vol. 38, no. 1, pp. 19-31, 2010.

[17]T. Dingsøyr, D. Falessi, and K. Power, "Agile development at scale: the next frontier," IEEE Software, vol. 36, no. 2, pp. 30-38, 2019.

[18]L. K. S. Roland, Terje Aksel; Sæbø, Johan Ivar; Eric Monteiro, "P for Platform," Scandinavian Journal of Information Systems, vol. 30, no. 2, 2018. 
[19]C. Cennamo, and J. Santaló, “Generativity tension and value creation in platform ecosystems," Organization Science, vol. 30, no. 3, pp. 617-641, 2019.

[20]J. Ju, L. Liu, and Y. Feng, "Public and private value in citizen participation in E-governance: Evidence from a government-sponsored green commuting platform," Government Information Quarterly, vol. 36, no. 4, pp. 101400, 2019.

[21]T. Eisenmann, G. Parker, and M. W. Van Alstyne, "Strategies for two-sided markets," Harvard business review, vol. 84, no. 10, pp. 92, 2006.

[22]G. G. Parker, M. W. Van Alstyne, and S. P. Choudary, Platform Revolution: How Networked Markets Are Transforming the Economyand How to Make Them Work for You: WW Norton \& Company, 2016.

[23]A. Tiwana, B. Konsynski, and A. A. Bush, "Research commentary-Platform evolution: Coevolution of platform architecture, governance, and environmental dynamics," Information Systems Research, vol. 21, no. 4, pp. 675-687, 2010.

[24]E. Bonsón, S. Royo, and M. Ratkai, 'Citizens' engagement on local governments' Facebook sites. An empirical analysis: The impact of different media and content types in Western Europe," Government information quarterly, vol. 32, no. 1, pp. 52-62, 2015.

[25]S. M. Zavattaro, P. E. French, and S. D. Mohanty, "A sentiment analysis of US local government tweets: The connection between tone and citizen involvement," Government information quarterly, vol. 32, no. 3, pp. 333-341, 2015.

[26]L. C. Hand, and B. D. Ching, "Maintaining neutrality: A sentiment analysis of police agency Facebook pages before and after a fatal officerinvolved shooting of a citizen," Government Information Quarterly, vol. 37, no. 1, pp. 101420, 2020.

[27]C. Nam, "Behind the interface: Human moderation for deliberative engagement in an eRulemaking discussion," Government Information Quarterly, vol. 37, no. 1, pp. 101394, 2020.

[28]L. Danneels, S. Viaene, and J. Van den Bergh, "Open data platforms: Discussing alternative knowledge epistemologies," Government Information Quarterly, vol. 34, no. 3, pp. 365378, 2017/09/01/, 2017.

[29]M. Kassen, “A promising phenomenon of open data: A case study of the Chicago open data project," Government Information Quarterly, vol. 30, no. 4, pp. 508-513, 2013.
[30]E. Ruijer, S. Grimmelikhuijsen, and A. Meijer, "Open data for democracy: Developing a theoretical framework for open data use," Government Information Quarterly, vol. 34, no. 1, pp. 45-52, 2017.

[31]T. O'Reilly, "Government as a Platform," Innovations: Technology, Governance, Globalization, vol. 6, no. 1, pp. 13-40, 2011.

[32]P. Dunleavy, H. Margetts, S. Bastow, and J. Tinkler, "New public management is dead-long live digital-era governance," Journal of public administration research and theory, vol. 16, no. 3, pp. 467-494, 2006.

[33]J. Fishenden, and M. Thompson, "Digital government, open architecture, and innovation: why public sector IT will never be the same again," Journal of public administration research and theory, vol. 23, no. 4, pp. 977-1004, 2012.

[34]OECD, OECD Recommendation on Digital Government Strategies, OECD, OECD Publishing, Paris, 2014.

[35]S. Vågeng, Et NAV med muligheter, Ministry of Labor and Social Affairs, https://www.regjeringen.no/no/aktuelt/ekspertgr uppens-forslag-til-et-bedre-nav/id2404844/, 2015.

[36]H. K. Klein, and M. D. Myers, "A set of principles for conducting and evaluating interpretive field studies in information systems," MIS quarterly, pp. 67-93, 1999.

[37]A. Langley, "Strategies for theorizing from process data," Academy of Management, 1999.

[38]M. M. Mikalsen, Nils B; Stray, Viktoria; Nyrud, Helga, "Agile digital transformations: a case study of interdependencies," in ICIS, 2018.

[39]J. Torfing, E. Sørensen, and A. Røiseland, "Transforming the Public Sector Into an Arena for Co-Creation: Barriers, Drivers, Benefits, and Ways Forward," Administration \& Society, vol. 51, no. 5, pp. 795-825, 2016.

[40]A. Gawer, "Bridging differing perspectives on technological platforms: Toward an integrative framework," Research Policy, vol. 43, no. 7, pp. 1239-1249, 2014/09/01/, 2014.

[41]M. D. de Jong, S. Neulen, and S. R. Jansma, 'Citizens' intentions to participate in governmental co-creation initiatives: Comparing three co-creation configurations," Government information quarterly, vol. 36, no. 3, pp. 490-500, 2019. 